Pan, Yii-Wen; Liao, Jyh-Jong; Li, P. C.; Li, G. W.

Verfügbar unter / Available at:

https://hdl.handle.net/20.500.11970/100270

Vorgeschlagene Zitierweise / Suggested citation:

Pan, Yii-Wen; Liao, Jyh-Jong; Li, P. C.; Li, G. W. (2010): A Microscopic Study on Soft Rock Erosion by Using Particle Flow Simulation. In: Burns, Susan E.; Bhatia, Shobha K.; Avila, Catherine M. C.; Hunt, Beatrice E. (Hg.): Proceedings 5th International Conference on Scour and Erosion (ICSE-5), November 7-10, 2010, San Francisco, USA. Reston, Va.: American Society of Civil Engineers. S. 519-529. 


\title{
A Microscopic Study on Soft Rock Erosion by Using Particle Flow Simulation
}

\author{
Y.W. Pan ${ }^{1,2}$, M. ASCE, J.J. Liao ${ }^{1,2}$, P.C. Li ${ }^{2}$, and G.W. Li ${ }^{1}$ \\ ${ }^{1}$ Department of Civil Engineering, National Chiao Tung University, Hsinchu, Taiwan \\ 30010 . \\ ${ }^{2}$ Disaster Prevention \& Water Environment Research Center, National Chiao Tung \\ University, Hsinchu, Taiwan 30010.
}

\begin{abstract}
Few existing erosion models have looked into the micromechanics of rock erosion. This study made use of particle flow simulation to model the erosion process of soft rock in microscopic scale which may be regarded as a "virtual erosion test". In the simulation, rock material is modeled as a granular assemblage with inter-particle bonding; the erosion process is simulated as particles' release due to de-bonding. Saltating abrasion can be a consequence of gravel traveling along with water flow and striking on the riverbed; the impact results in the local failure and causes abrasion. The major factors affecting the erosion rate are examined through a series of virtual erosion tests. Simulated results show that more de-bonded particles may occur for a condition with higher impact speed, higher impact angle, larger gravel size, higher Young's modulus, or lower rock strength. It appears that particle flow simulation is able to capture the mechanism of abrasion by saltating gravel.
\end{abstract}

\section{INTRODUCTION}

Although rock bed is often considered a lot more resistant to erosion than alluvium, exposed soft-rock bed may be subjected to significant erosion (e.g., Huang, et al., 2008). In several notable cases in Taiwan, intensive erosion occurred in soft rock river-bed soon after the boulder or gravel cover was eroded away as a result of the change in stream power due to an abrupt headcut because of a man-made cross-river structure or a sudden uplift by faulting. The continuous erosion in rock-bed may largely endanger the stability of cross-river structure such as bridge piers and weirs; it may also accelerate river-bed incision. The mechanisms for the scouring processes in soft rock deserve serious attention for engineering concerns. 
Soft rocks belong to a category of weak rocks (ISRM, 1981), often considered as a "marginal" or "transitional" geo-material (i.e. between soils and brittle rocks) (Johnston, 1993; Oliveira, 1993). They usually present unfavorable characteristics including poor cementation, low strength and high deformability (Johnston, 1993) due to insufficient lithification. The outcrops in the northern and western foothills of Taiwan, composed mostly of weakly cemented sedimentary rocks formed in the epochs from late Miocene to Pleistocene, exhibit the typical characteristics of soft rocks. Their unconfined strengths are often under $25 \mathrm{MPa}$. For typical soft rock formations, the presence of fractures or joints is usually not very significant.

The mechanisms of rock erosion have been studied by many researchers (e.g., Whipple, et al., 2000). In general, the major mechanisms of rock erosion can be classified into (1) hydraulic erosion of un-jointed intact rock, (2) hydraulic erosion of jointed rock masses (plucking), (3) abrasive erosion due to bed load or suspended load, and (4) cavitation. In some cases, dissolution and weathering of rock material can also result in the mass loss of rock material exposed in water current

Existing models for the erosion-rate estimation of rock-bed may be rational (e.g., Howard, and Kerby, 1983), empirical (Annandale, 2006) or mechanical-process based (e.g., Sklar and Dietrich, 2004). The hydraulic erosion rate of rock-bed is often described by an empirical erosion law that approximates the erosion rate as a power function of bed shear stress or stream power; these types of empirical law of erosion rate can be generalized into "stream-power family of models" (Whipple \& Tucker, 1999). A model may also include a threshold shear stress for incision and may consider the influence of sediment load on incision rate. Many of these models are intended for describing erosion rate in a reach scale.

Index based model such as the one developed by Annandale (1995) is available for estimate the erodibility of rock-bed by hydraulic erosion in terms of the so-called "erodibility index". The erodibility index takes into account major factors influencing the erodibility of rock-bed. Four indices include the material strength, block/grain size, joint strength, and joint structure of rock masses are taken into account. The definition of the erodibility index is the multiplication of these four individual indices. Annandale (2006) also suggested an empirical relation that correlates the erodibility index and the threshold stream power causing erosion.

Abrasive erosion or abrasion is a result of wearing by bed-load particles traveling along with current. In strong current, saltating bed-load particles may strike on the riverbed and cause the fracture and deaggregation of material on the 
rock surface; this mechanism is called "saltation abrasion". The bed load may either provide a cover effect (protecting rock-bed from abrasion) or serve as a tool effect (enhancing abrasion) (Gilbert, 1877; Foley, 1980). The rate of saltation abrasion is affected by the grain size of bed load, the trajectory of particle, particle impact velocity, sediment flux, and the rock resistance to abrasion.

Sklar and Dietrich (2004) developed a mechanically based model for modeling the abrasion by saltating bed-load particles. The fundamental concept of this model states that the bedrock incision rate due to particle saltation can be expressed as the product of (1) the volume of removed (disintegrated) rock per particle impact $V_{i},(2)$ the rate of particle impacts per unit area per unit time $I_{r}$, and (3) the fraction of exposed bedrock $F_{e}$. The first term $V_{i}$ depends on impact characteristics (impact energy level, impact direction, particle size, etc) and the rock resistance against particle impact; $V_{i}$ is expressed as the transferred impact (excess) kinetic energy divided by the required energy to erode a unit rock volume $\varepsilon_{v}$. Sklar and Dietrich (2004) assumed that only the kinetic energy due to normal component of impact velocity is effective for saltating abrasion; the effect of cutting wear affected by the tangential component of impact velocity is neglected. The required energy $\varepsilon_{v}$ is assumed proportional to the stored elastic strain energy relating to the tensile strength $\sigma_{\mathrm{T}}$ and Young's modulus $\mathrm{E}$ of rock material expressed as $\varepsilon_{\mathrm{V}}=\mathrm{k}_{\mathrm{v}} \frac{\sigma_{\mathrm{T}}^{2}}{2 \mathrm{E}}$ in which $\mathrm{k}_{\mathrm{v}}$ is a proportionality constant. The second term $I_{r}$ is a function of flux of bed load particles and the trajectory of particle motion. The last term $F_{e}$ depends on sediment transport capacity.

The quantitative estimation of the bedrock incision rate based on this model relies on the close estimation of $V_{i}$ which is very much related to the micromechanics of the rock material subjected to an impact loading. To date, very few studies have looked into the micromechanics of rock erosion. The present work attempts to model the saltation-abrasion process of soft rock in microscopic scale by using particle flow simulation to explore the fundamental mechanisms of abrasion due to gravel saltation on rock river-bed.

\section{METHOD OF NUMERICAL SIMULATION}

The particle flow simulation in this work made use of the code PFC ${ }^{3 \mathrm{D}}$ (ITASCA, 2006) that represents a granular material as an assemblage of spherical balls. PFC ${ }^{3 D}$ belongs to the category of numerical method of distinct element methods dealing 
with the mechanics of a dis-continuum (Cundall and Strack, 1979). The distinct element method is an explicit numerical method that successively solve for the Law of Motion for each particles and the inter-particle contact force-displacement relation in a particles' assemblage.

\section{Modeling of Rock Material}

In this study, a rock material is modeled as a particles' assemblage with assigned inter-particle bonding. The particles' assemblage contains roughly 11000 balls with radius in the range of $0.2-0.3 \mathrm{~mm}$ to model a virtual rock specimen of the size 150 $\mathrm{mm}$ by $100 \mathrm{~mm}$ by $80 \mathrm{~mm}$ bounded by walls. Fig. 1 shows the particles' assemblage used in this work. The target porosity is controlled by slightly expanding the particles' radius. Rock material with a specific set of macroscopic engineering properties can be modeled by assigning an appropriate set of microscopic parameters to the particles' assemblage. Required microscopic parameters may contain particle parameters including density, particle size, Young's modulus, and inter-particle parameters including bonding-strength parameters, contact stiffness, and contact frictional coefficient.

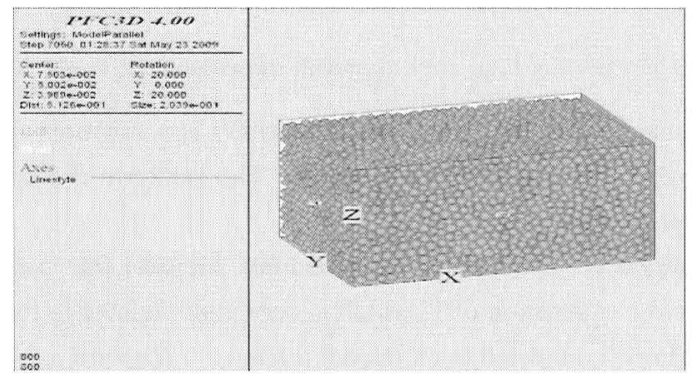

Figure 1. The assemblage of particles.

Microscopic parameters influence the macroscopic mechanical properties in predicable trends. Young's modulus is roughly proportional to the microscopic Young's modulus; also increases with an increase in either contact normal stiffness or friction coefficient. Poisson's ratio decreases with the increasing ratio between contact normal stiffness and shear stiffness. Unconfined strength is roughly proportional to the bonding strength. Friction angle increases with increasing frictional coefficient. 
To model a rock material, the microscopic parameters were assigned so that the numerically simulated stress-strain curves for common laboratory tests (e.g., triaxial compression tests) can be close enough to the ones actually obtained by laboratory tests on the material. Soft rock often has its uniaxial compressive strength under 25 MPa. For illustration, Fig. 2 shows the stress-strain curves corresponding to three different uniaxial compressive strengths with a similar Young's modulus.

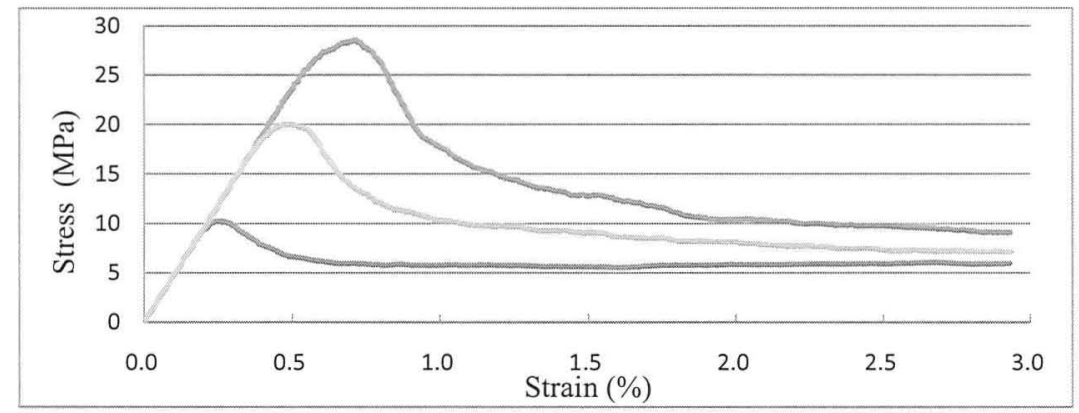

Figure 2. Simulated stress-strain curves for triaxial compression tests with various confining pressures.

\section{Modeling of Rock Abrasion}

The numerical simulation aims to model the process of rock erosion and can be regarded as a "virtual erosion test". In the numerical simulation, the abrasion process is a result of particles' release due to de-bonding. Both bed shear acting on the rock surface or impact arising from saltating gravel can trigger local inter-particle bonding failure so that results in rock erosion or abrasion. To model abrasion due to gravel saltation, a particle which is represented as a spherical ball, much larger than the sizes of grains (also represented by balls) of the rock material, was allowed to hit the surface of the virtual rock specimen. The generated stress wave, if large enough, may result in inter-particle de-bonding or breakage adjacent to the location of impact.

\section{RESULTS OF SIMULATION}

Fig. 3 demonstrates the simulated results for saltating abrasion in sequential stages. Fig.3(a)-(d), respectively, show the stage for the approaching gravel, the moment of impact, the rebound off the surface, and the flush-away of de-bonded 
particles. As noted in Fig. 3, the impact of saltating gravel onto the rock surface results in a clustered zone of de-bonding particles under the impact point. Once de-bonded, those released particles can be moved away by water current so that causes erosion.

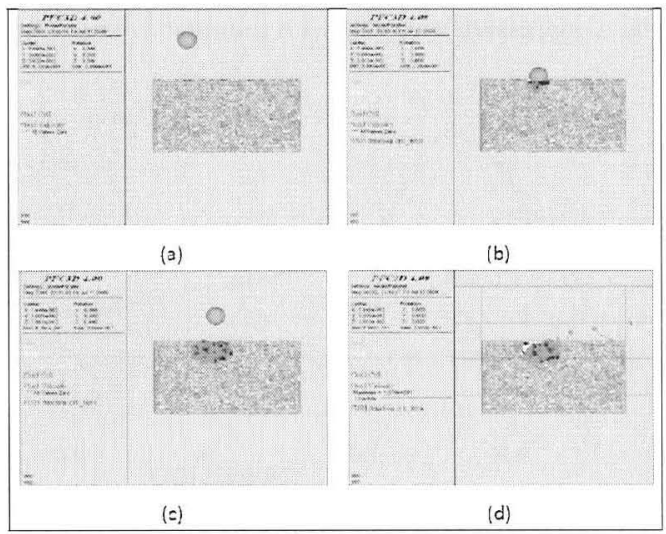

Figure 3. Simulated results for saltating abrasion in successive stages.

The amount of abrasion due to saltation is largely dependent on the transfer of impact kinetic energy and the rock resistance against abrasion. The transfer of impact kinetic energy is affected by the mass, the speed and the impact direction of the saltating gravel. Either a larger saltating particle or a higher traveling speed will have a higher kinetic energy so that will have a higher potential to damage the impacted rock surface.

According to the wear theory of Bitter (1963 a \& b), the vertical component of velocity can produce the deformation and fatigue failure of material so that results in the so called "deformation wear"; while the tangential component of velocity can cause shearing failure of material so that results in the so called "cutting wear". Impact at a higher angle (with respect to the tangential direction of contact force) has a higher normal component of velocity; and vice versa. The model of Sklar and Dietrich (2004) neglects the cutting wear of saltating gravel; only deformation wear is taken into account in their model. The rock resistance against abrasion is expressed as stored elastic strain energy in terms of $\varepsilon_{\mathrm{V}}=\mathrm{k}_{\mathrm{v}} \frac{\sigma_{\mathrm{T}}^{2}}{2 \mathrm{E}}$ in their model. 
This relation suggests that the required energy to erode a unit rock volume is proportional to the square of the tensile strength and inversely proportional to the Young's modulus of rock material.

To explore the factors affecting the potential abrasion due to saltating gravel, a series of simulation were carried out by changing a series of variables including the uniaxial compressive strength $\sigma_{c}$ and modulus of rock material $E$, gravel size $D$, incident angle $\theta$, and impact velocity $U_{i}$. The considered range of $\sigma_{c}$ is within the typical strength of soft rock. The range of gravel size is within $10 \mathrm{~mm}$ and $40 \mathrm{~mm}$. Two different incident angles, 30 degrees and 60 degrees with respect to the tangential direction are modeled. The modeled approaching velocity of saltating gravel is within $1 \mathrm{~m} / \mathrm{sec}$ and $10 \mathrm{~m} / \mathrm{sec}$. The number of de-bonded particles after impact $N_{d b}$ for each case was counted to evaluate the potential erodible volume after the strike of a saltating particle. The average volume for each particle is about 6.54 $\times 10^{-11} \mathrm{~m}^{3}$.

Fig. 4 shows $N_{d b}$ versus gravel size with a same impact velocity at two different incident angles $\theta$ for various $\sigma_{c}$ (under the condition of $U_{i}=6 \mathrm{~m} / \mathrm{s}$ ). The solid curves and the dashed curves are for $\theta=30^{\circ}$ and $60^{\circ}$, respectively. The $30^{\circ}$ incident angle can be regarded as a low-angle impact; while the $60^{\circ}$ incident angle can be regarded as high-angle impact. The comparison of the solid and dashed curves reveals that high-angle impact produces significantly more inter-particle de-bonding damage in the material than the case of low-angle impact. It is evident that normal component of impact velocity significantly does play a much more important role on saltating abrasion than the tangential component of impact velocity. Fig. 4 also reveals that rock material with a higher strength will have a higher resistance against abrasion so that $N_{d b}$ has a smaller value.

Fig. 5 shows $N_{d b}$ versus impact velocity for various gravel sizes (under the conditions of $\sigma_{c}=12 \mathrm{MPa}$ and $\theta=60^{\circ}$ ). It appears that $N_{d b}$ increases with impact velocity and gravel size. Saltating gravel with a higher impact velocity has a higher kinetic energy to break the inter-particle bonding adjacent to the impact point. A highly nonlinear increase of $N_{d b}$ with raising impact velocity is notable. It appears the impact gravel velocity plays a major effect on the de-bonding or breakage of rock material after saltating impact. 


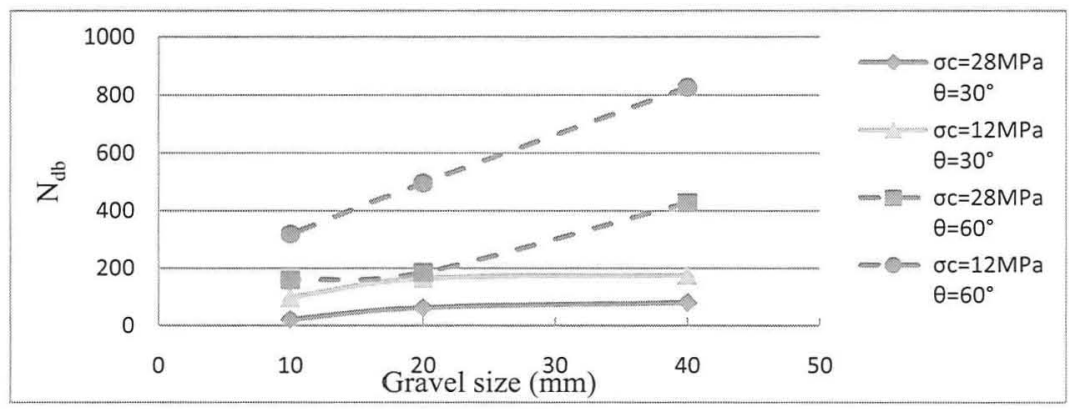

Figure 4. Number of de-bonded particles versus gravel size for various incident angle and rock strength.

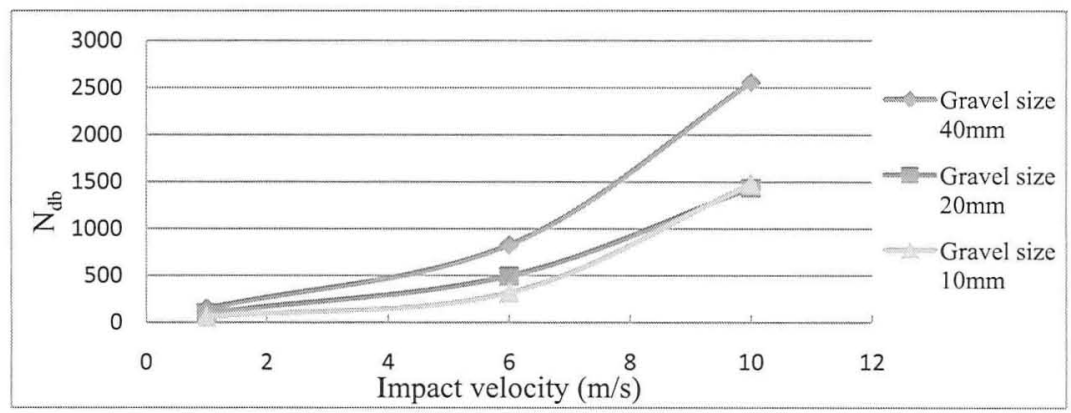

Figure 5. Number of de-bonded particles versus impact velocity for various sizes of saltating gravel (with $60^{\circ}$ incident angle).

The mechanical properties of bed-rock influence the eroded rock volume after each impact. Fig. 6(a) presents the influence of the Young's modulus of rock material on $N_{d b}$ (under the conditions of $U_{i}=6 \mathrm{~m} / \mathrm{s}$ and $\theta=60^{\circ}$ ). Under same conditions of the saltating gravel; $N_{d b}$ nonlinearly rises with the increase in the Young's modulus. Fig. 6(b) shows the influence of tensile strength of rock material on $N_{d b}$. Under same conditions of a saltating gravel, $N_{d b}$ nonlinearly decreases with the increase in the tensile strength. The kinetic energy remains the same under same conditions of the saltating gravel. $N_{d b}$ should be inversely proportion to the required energy to erode a unit rock volume $\varepsilon_{v}$, but not necessarily following the stored elastic strain energy expressed as the form of $\varepsilon_{\mathrm{V}}=\mathrm{k}_{\mathrm{V}} \frac{\sigma_{\mathrm{T}}^{2}}{2 \mathrm{E}}$. 

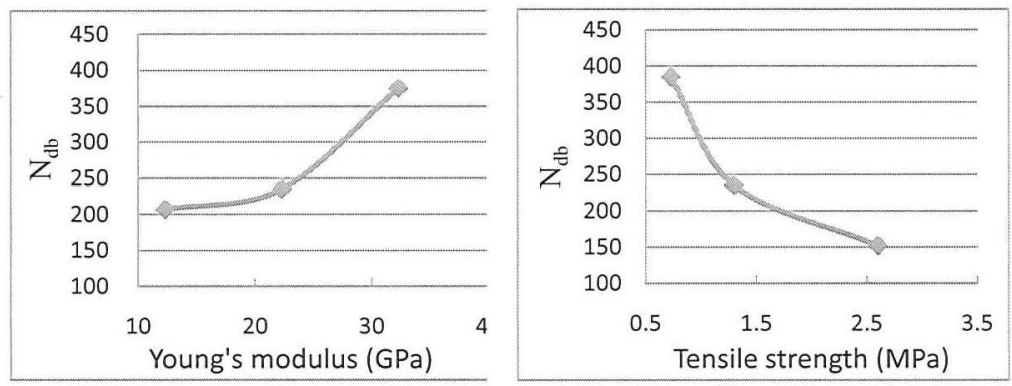

Figure 6. Number of de-bonded particles versus (a) Young's modulus and (b) Tensile strength.

\section{SUMMARY AND CONCLUSION}

This work made use of particle flow simulation to model the abrasion process of soft rock in microscopic scale. Its objectives are to model the process of abrasion due to gravel saltation, and to explore the micromechanics of the erosion process. A rock material is modeled as a granular assemblage with inter-particle bonding. This type of simulation can be regarded as a "virtual erosion test". To model the abrasion due to gravel saltation, the simulation allows a saltating particle to hit the surface of the virtual rock specimen. After the impact, the stress wave results in the inter-particle de-bonding or breakage under the impact point so that causes rock erosion near the surface. The erodible volume after each impact by saltating gravel should be proportional to the number of de-bonded particles.

The abrasive amount due to each saltation impact depends on the transferred impact energy and the rock resistance. To explore the major factors affecting potential abrasion due to saltating gravel, a series of simulation were carried out by changing variables including mechanical properties of rock material, gravel size, incident angle, and impact velocity. It is shown that the number of de-bonded particles will increase with increasing gravel size, incident angle, and impact velocity. The gravel size and impact velocity contribute to the impact kinetic energy that can be transferred to rock bed so that damages the rock material. A higher incident angle results in higher normal component of impact velocity so that causes a higher degree of deformation wear. For the influences of mechanical properties of rock material, a rock material with higher rock strength (both in compressive and tension) 
will offer higher resistance to abrasion by impact so that causes a less amount of erodible volume after each impact; while the erodible volume after each impact tends to rise with an increase in the Young's modulus of rock material.

\section{REFERENCES}

Annandale, G.W. (1995). "Erodibility.", Journal of Hydraulic Research, 33(4): 471-494.

Annandale, G.W. (2006). "Quantification of the Erosive Capacity of Water." Proc. $3 r d$ Int. Conf. on Scour and Erosion, Amsterdam, Netherlands: 1-6.

Bitter, J.G.A. (1963a). “A study of erosion phenomenon, Part I.” Wear, 6(1): 5-21.

Bitter, J.G.A. (1963b)."A study of erosion phenomenon, Part II." Wear, 6(3):169-190.

Cundall, P., O. Strack (1979). "A discrete numerical model for granular assemblies." Geotechnique, 29(1): 47-65.

Foley, M.G. (1980). "Bedrock incision by streams." Geological Society of America Bulletin.,Part II, 91: 2189- 2213.

Gilbert, G. K. (1877). Report on the Geology of the Henry Mountains : Geographical and Geological Survey of the Rocky Mountain Region, 160p.

Howard, A.D. and Kerby, G. (1983) "Channel changes ub badlands." Geol. Soc. of America Bulletin, 94:739-752.

Huang, M.W., Cheng, M.H., Liao, J.J., and Pan, Y.W. (2008). "Rapid bedrock erosion in the Taan River." Proc. $4^{\text {th }}$ Int. Conf. on Scour and Erosion, Tokyo, Japan.

ISRM. (1981). "Rock characterization testing and monitoring." ISRM Suggested Methods, Pergamon Press, New York.

ITASCA (2006). Manuals of PFC ${ }^{3 D}$.

Johnston, I.W. (1993). "Soft tock engineering." Comprehensive Rock Engineering: Principles, Practice \& Project (V. 1), Pergamon Press: 367-393.

Oliveira R. (1993 ) "Weak rock materials." The Engineering Geology of Weak Rock: 5-15.

Sklar, L. S., W. E. Dietrich (2004). “A mechanistic model for river incision into bedrock by saltating bed load." Water Resources Research, 40(6): 063011-063021.

Whipple, K.X. and Tucker, G.E. (1999). "Dynamics of the stream-power river incision model." Journal of Geophysical Research, 104: 17661-17674. 
Whipple, K.X., G.S. Hancock, R.S. Anderson, (2000). "River incision into bedrock: Mechanics and relative efficacy of plucking, abrasion, and cavitation." Geol. Soc. of America Bulletin, 112(3): 490-503. 